\title{
ARTICLE
}

Received 15 Mar 2013 | Accepted 15 May 2013 | Published 14 Jun $2013 \quad$ DOl: 10.1038/ncomms3014

\section{A ladder polysilane as a template for folding palladium nanosheets}

Yusuke Sunada1,2, Ryohei Haige ${ }^{2}$, Kyohei Otsuka ${ }^{3}$, Soichiro Kyushin ${ }^{3}$ \& Hideo Nagashima ${ }^{1,2}$

Although discrete nano-sized compounds consisting of a monolayer sheet of multiple atoms have attracted much attention, monolayer transition metal nanosheets are difficult to access. Here we report a template synthesis of the folding metal nanosheet (2) consisting of 11 palladium atoms by treatment of a ladder polysilane, decaisopropylbicyclo[2.2.0]hexasilane (1), with $\mathrm{Pd}\left(\mathrm{CN}^{t} \mathrm{Bu}\right)_{2}$. Crystallographic analysis reveals that the compound is composed of two monolayer $\mathrm{Pd}_{7}$ sheets sharing three palladium atoms at the junction. Each $\mathrm{Pd}$ atom is stabilized by $\mathrm{Pd}-\mathrm{Si} \sigma$-bonds, $\mathrm{Pd}-\mathrm{Pd}$ bonds and coordination of isocyanides. Ligand exchange of 2 from $\mathrm{CN}^{t} \mathrm{Bu}$ to $\mathrm{CN}\left(2,4,6-\mathrm{Me}_{3}-\mathrm{C}_{6} \mathrm{H}_{2}\right)$ is accompanied by structural rearrangement, leading to the formation of another folding $\mathrm{Pd}_{11}$ nanosheet (3) consisting of two edge-sharing $\mathrm{Pd}_{7}$ sheets. The shapes of the $\mathrm{Pd}_{7}$ sheets as well as the dihedral angle between the two $\mathrm{Pd}_{7}$ sheets are dependent on the substituent of the isocyanide ligand.

\footnotetext{
${ }^{1}$ Institute for Materials Chemistry and Engineering, Kyushu University and CREST, Japan Science and Technology Agency (JST), Kasuga, Fukuoka 816-8580, Japan. ${ }^{2}$ Graduate School of Engineering Sciences, Kyushu University, 6-1 Kasugakoen, Kasuga, Fukuoka 816-8580, Japan. ${ }^{3}$ Department of Chemistry and Chemical Biology, Graduate School of Engineering, Gunma University, Kiryu, Gunma 376-8515, Japan. Correspondence and requests for materials should be addressed to H.N. (email: nagasima@cm.kyushu-u.ac.jp).
} 
T he isolation of graphene from graphite, typically by scratching away multilayers of graphite, has made it possible to access a new form of carbon with nanosheet structures $^{1-4}$. Several metal oxides and sulphides having multilayered structures also form nanosheets by peeling off their monolayers ${ }^{5}$. These nanosheets show profoundly different physical properties from their precursors, eliciting much interest in nanoscience. These nanosheets suggest the possible preparation of transition metal nanosheets; however, the lack of precursors to which to apply mechanical separation suitable for isolation of monolayers prevents easy access to these compounds. The synthesis of relatively small transition metal nanosheets has attained some success in organometallic and inorganic chemistry $^{6-9}$. Among them, a novel methodology to synthesize $\mathrm{Pd}_{3}$ to $\mathrm{Pd}_{5}$ nanosheets was developed by Murahashi et al. ${ }^{10-16}$ using (poly)cyclic aromatic hydrocarbons as a template for the arrangement of $\mathrm{Pd}$ atoms in a two-dimensional sheet structure. The sandwich compound, $\left[\mathrm{Pd}_{5}(\text { naphthacene })_{2}\right]^{2+}$, is the largest palladium nanosheet reported to date ${ }^{10}$. Success of this template synthesis of transition metal nanosheets suggests a strategy to access new nanosheets using templates that force the metals into a planar arrangement owing to metal-metal bonding interactions.

In this paper, we report a ladder polysilane, decaisopropylbicyclo[2.2.0] hexasilane $(\mathbf{1})^{17-20}$, that serves as a template for two $\mathrm{Pd}_{11}$ clusters, $\mathbf{2}$ and $\mathbf{3}$, which are considered to be folding metal nanosheets having two planar $\mathrm{Pd}_{7}$ units. The array of $\mathrm{Pd}$ and $\mathrm{Si}$ atoms and the dihedral angle of the two $\mathrm{Pd}_{7}$ sheets are dependent on the substituent of the isocyanide ligand.

\section{Results}

Synthesis of folding $\mathbf{P d}_{11}$ nanosheet 2. Insertion of a $\mathrm{Pd}(\mathrm{CNR})_{2}$ species between a Si-Si bond of oligosilanes to give complexes of the type $(\mathrm{RNC})_{2} \mathrm{Pd}\left(\mathrm{SiR}_{3}\right)_{2}$ has been investigated extensively by Ito and coworkers ${ }^{21,22}$. These complexes serve as intermediates for catalytic transformations of oligosilanes. However, only a few cyclic oligosilanes were subjected to the study, and they were reportedly less reactive than their linear analogues even at elevated temperatures. Our new discovery, a ladder polysilane having seven $\mathrm{Si}-\mathrm{Si}$ bonds in a molecule, decaisopropylbicyclo[2.2.0]hexasilane (1), is highly reactive towards $\mathrm{Pd}\left(\mathrm{CN}^{t} \mathrm{Bu}\right)_{2}\left({ }^{t} \mathrm{Bu}=t\right.$-butyl), and the reaction unexpectedly leads to the formation of the $\mathrm{Pd}_{11}$ cluster 2. As shown in Fig. 1, treatment of 1 with 11 equivalents of $\mathrm{Pd}\left(\mathrm{CN}^{t} \mathrm{Bu}\right)_{2}$ in toluene at room temperature resulted in complete consumption of 1 after $18 \mathrm{~h}$. The product 2 was isolated as dark green crystals suitable for crystallography in $65 \%$ yield by recrystallization from toluene/ pentane at $-35^{\circ} \mathrm{C}$. The molecular structure of 2 (vide infra) suggests that oxidative addition of $\mathrm{Pd}\left(\mathrm{CN}^{t} \mathrm{Bu}\right)_{2}$ moieties into seven $\mathrm{Si}-\mathrm{Si}$ bonds in $\mathbf{1}$ explains the origin of seven Pd atoms in 2, and an additional four Pd atoms participate in the construction of the folding nanosheet structure. No intermediary species were visible in the reaction from $\mathbf{1}$ to 2 . Indeed, treatment of $\mathbf{1}$ with seven equivalents of $\mathrm{Pd}\left(\mathrm{CN}^{t} \mathrm{Bu}\right)_{2}$ resulted in exclusive formation of $2(65 \%)$ with recovery of $\mathbf{1}(35 \%)$.

Molecular structure of 2 . The molecular structure of $\mathbf{2}$ is depicted in Fig. 2a,b and Supplementary Figs S1 and S2. The molecular structure of $\mathrm{Pd}_{11}$ cluster 2 can be regarded as one large folding nanosheet containing eleven palladium atoms or two small nanosheets $\left(\mathrm{Pd}_{7}\right.$ sheet I and $\mathrm{Pd}_{7}$ sheet II in Fig. 2a) consisting of seven palladium atoms each, sharing three palladium atoms at the junction. The dihedral angle between sheets I and II is $37.7^{\circ}$ (Fig. $2 \mathrm{c}$ and Supplementary Fig. S3). Each $\mathrm{Pd}_{7}$ sheet contains two silylene moieties, $\operatorname{Si}^{i} \operatorname{Pr}_{2}\left({ }^{i} \operatorname{Pr}=i\right.$-propyl), which are located in the plane of the $\mathrm{Pd}_{7}$ sheet, whereas one silylyne group, $\mathrm{Si}^{i} \mathrm{Pr}$, is located out of the plane as described later in more detail. Four palladium atoms at the edge of the $\mathrm{Pd}_{7}$ sheet are bonded to the terminal isocyanide ligands. Three linearly assembled $\mathrm{Pd}$ atoms, $\operatorname{Pd}(5), \operatorname{Pd}(6)$ and $\operatorname{Pd}(7)$, lie on the junction (Fig. 2d), and two $\mathrm{CN}^{t} \mathrm{Bu}$ ligands bridge the $\mathrm{Pd}(5)-\mathrm{Pd}(6)$ and $\operatorname{Pd}(6)-\operatorname{Pd}(7)$ bonds to enhance the Pd-Pd interactions.

Synthesis of another folding $\mathbf{P d}_{11}$ nanosheet 3. To our surprise, the $\mathrm{CN}^{t} \mathrm{Bu}$ ligands were reactive towards ligand exchange by other isocyanide ligands, for example, $\mathrm{CN}\left(2,4,6-\mathrm{Me}_{3}-\mathrm{C}_{6} \mathrm{H}_{2}\right)$. Treatment of 2 with ten equivalents of $\mathrm{CN}\left(2,4,6-\mathrm{Me}_{3}-\mathrm{C}_{6} \mathrm{H}_{2}\right)$ in toluene at $-35^{\circ} \mathrm{C}$ for $12 \mathrm{~h}$ resulted in quantitative displacement of all of the $\mathrm{CN}^{t} \mathrm{Bu}$ ligands with $\mathrm{CN}\left(2,4,6-\mathrm{Me}_{3}-\mathrm{C}_{6} \mathrm{H}_{2}\right)$ to produce the new $\mathrm{Pd}_{11}$ cluster 3 in 55\% yield after recrystallization from ether (Fig. 1). X-ray structure analysis revealed that compound 3 also has a folding $\mathrm{Pd}_{11}$ nanosheet structure similar to 2 (Fig. 2e,f and Supplementary Figs S4 and S5). However, the dihedral angle $\left(47.7^{\circ}\right.$ ) between the two $\mathrm{Pd}_{7}$ sheets (Fig. $2 \mathrm{~g}$ and Supplementary Fig. S6) is significantly different from that in 2. Similar to 2, each $\mathrm{Pd}_{7}$ nanosheet is supported by two silylene units in the plane and one silylyne moiety out of the plane; however, the array of Pd and $\mathrm{Si}$ atoms is different from that in $\mathbf{2}$ (vide infra). Three palladium atoms at the edge of the $\mathrm{Pd}_{7}$ sheet are bonded to terminal isocyanide ligands, whereas five $\operatorname{Pd}$ atoms, $\operatorname{Pd}(1), \operatorname{Pd}(5), \operatorname{Pd}(6), \operatorname{Pd}(7)$ and $\operatorname{Pd}(8)$, aligning in a slightly curved line are bound to four bridging isocyanide ligands (Fig. $2 \mathrm{~h}$ ).

Detailed molecular structures of 2 and 3. Several unique points should be noted in the molecular structures of $\mathbf{2}$ and 3 . First, both 2 and 3 consist of eleven palladium atoms, six organosilyl moieties and ten isocyanide ligands with formula $\mathrm{Pd}_{11}\left(\mathrm{Si}^{i} \mathrm{Pr}_{2}\right)_{4}$ $\left(\mathrm{Si}^{i} \mathrm{Pr}\right)_{2}(\mathrm{CNR})_{10}$. Second, both $\mathbf{2}$ and $\mathbf{3}$ have a pseudo twofold axis
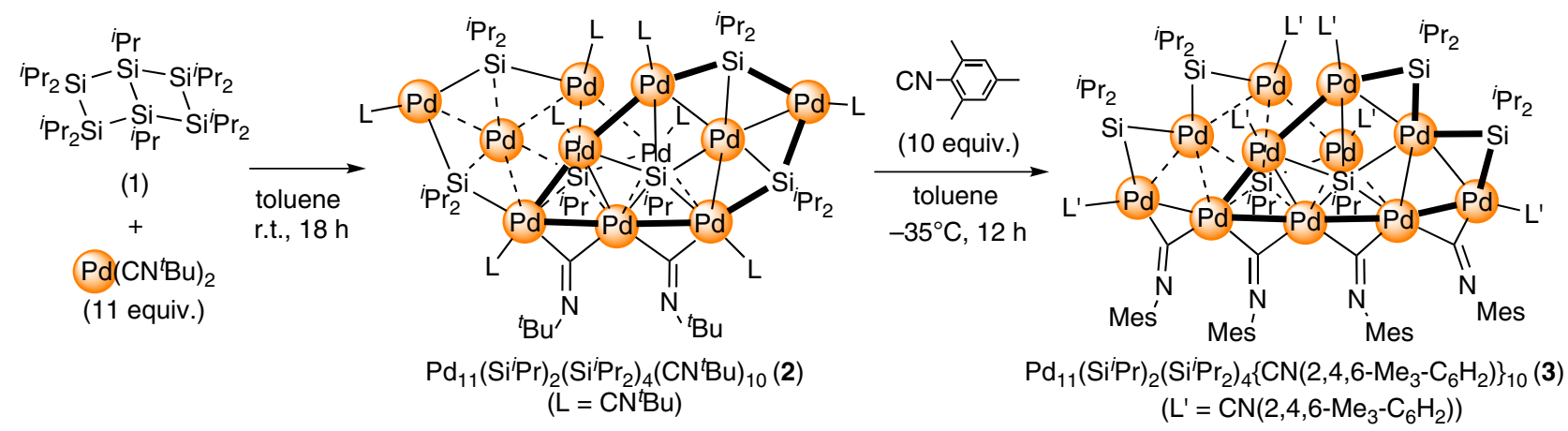

Figure 1 | Synthesis of $\mathbf{2}$ and 3. Synthesis of $\mathbf{2}$ by using a ladder polysilane (1) as the template, and synthesis of $\mathbf{3}$ by ligand exchange and skeletal rearrangement. r.t., room temperature. 
a

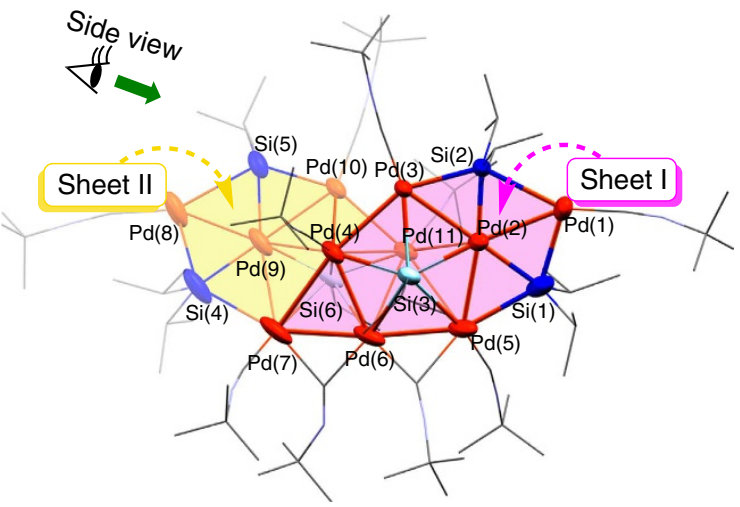

b

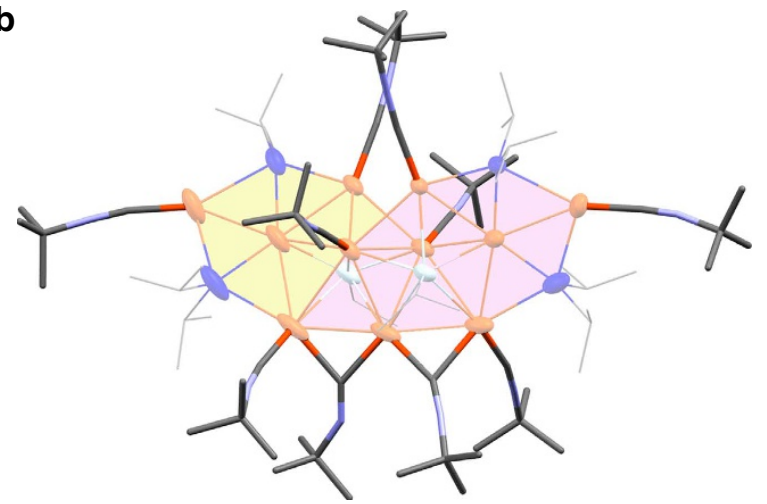

C

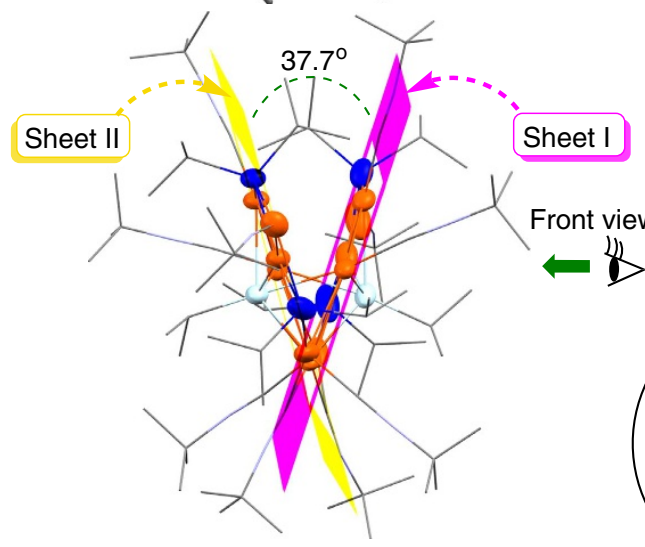

d

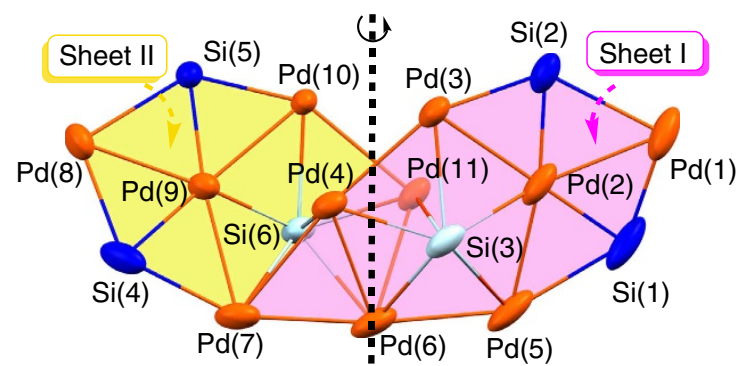

e

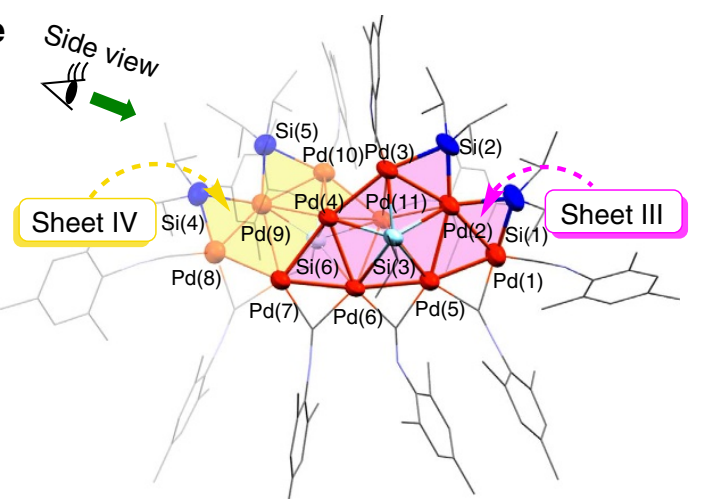

f

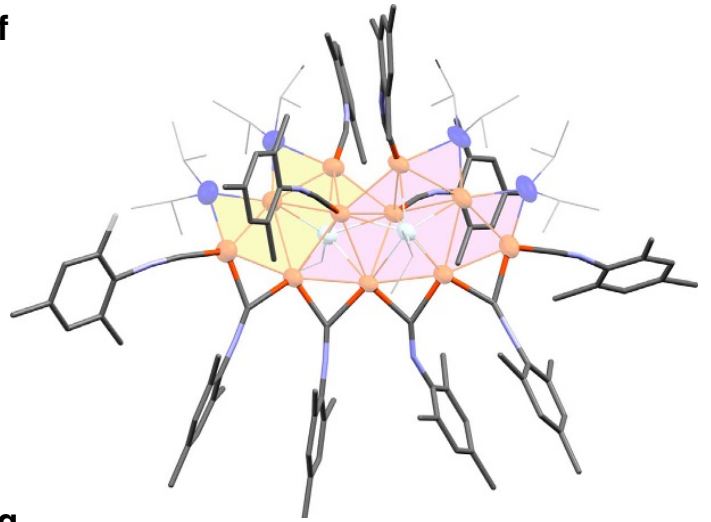

g

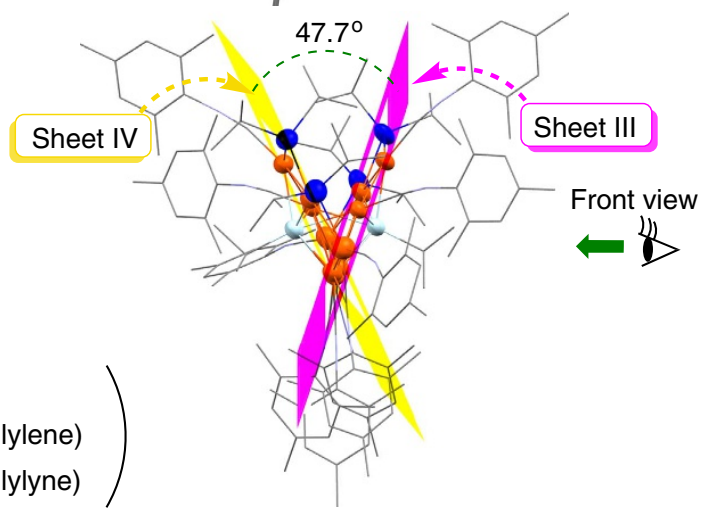

$\left(\begin{array}{l}\bigcirc=\mathrm{Pd} \\ \mathbf{O}=\mathrm{Si} \text { (silylene) } \\ \mathrm{C} \mathrm{Si} \text { (silylyne) }\end{array}\right)$

h

Pseudo 2-fold axis

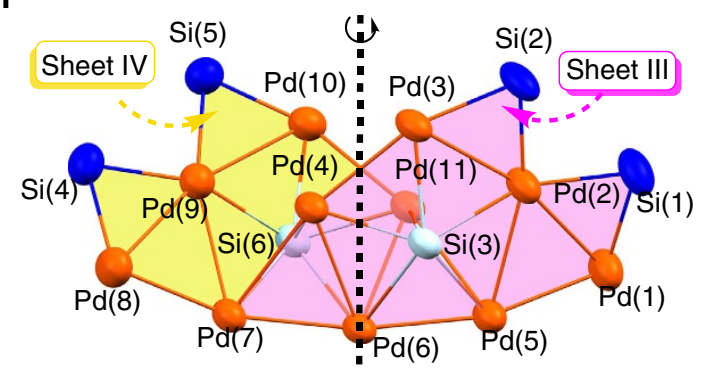

Figure $\mathbf{2}$ | Molecular structures of $\mathbf{2}$ and 3. (a) Front view of $\mathbf{2}\left(\mathrm{Pd}_{11} \mathrm{Si}_{6}\right.$ core was emphasized). (b) Front view of $\mathbf{2}$ ( $\mathrm{CN}{ }^{t} \mathrm{Bu}$ ligands were emphasized). (c) Side view of 2. (d) Array of $\mathrm{Pd}$ and $\mathrm{Si}$ atoms of 2. (e) Front view of $\mathbf{3}\left(\mathrm{Pd}_{11} \mathrm{Si}_{6}\right.$ core was emphasized). (f) Front view of $\mathbf{3}\left(\mathrm{CN}\left(2,4,6-\mathrm{Me}_{3}-\mathrm{C}_{6} \mathrm{H}_{2}\right)\right.$ ligands were emphasized). (g) Side view of $\mathbf{3}$. (h) Array of Pd and Si atoms of $\mathbf{3}$. Probability ellipsoids shown at $50 \%$.

passing through the $\operatorname{Pd}(6)$ atom and the midpoint of the $\operatorname{Pd}(4)$ and $\mathrm{Pd}(11)$ atoms as shown in Fig. 2d,h. Third, each half, that is, $\mathrm{Pd}_{7}$ sheets I and II in 2 and $\mathrm{Pd}_{7}$ sheets III and IV in $\mathbf{3}$, consists of a $\mathrm{Pd}_{7}\left(\mathrm{Si}^{i} \mathrm{Pr}_{2}\right)_{2}\left(\mathrm{Si}{ }^{i} \mathrm{Pr}\right)$ subunit. Owing to the pseudo- $C_{2}$-symmetric structures of $\mathbf{2}$ and $\mathbf{3}$, the $\mathrm{Pd}_{7}$ sheets I and II in $\mathbf{2}$ or the $\mathrm{Pd}_{7}$ sheets III and IV in 3 can be regarded as structurally equivalent. In fact, all of the $\mathrm{Pd}-\mathrm{Pd}, \mathrm{Pd}-\mathrm{Si}$ and $\mathrm{Pd}-\mathrm{C}$ distances and related bond angles in I or III are comparable to those of II or IV. In Fig. 3 are depicted the array of $\mathrm{Pd}$ and $\mathrm{Si}$ atoms in the $\mathrm{Pd}_{7}$ sheet $\mathrm{I}(\mathrm{a}-\mathrm{d})$ and the $\mathrm{Pd}_{7}$ sheet III (e and $\mathrm{f}$ ). For both $\mathrm{Pd}_{7}$ sheets I and III, the seven palladium and two silicon atoms of the $\mathrm{Pd}_{7}\left(\mathrm{Si}^{i} \mathrm{Pr}_{2}\right)_{2}\left(\mathrm{Si}^{i} \mathrm{Pr}\right)$ subunit are located in the same plane to form the planar $\mathrm{Pd}_{7} \mathrm{Si}_{2}$ nanosheet 
a
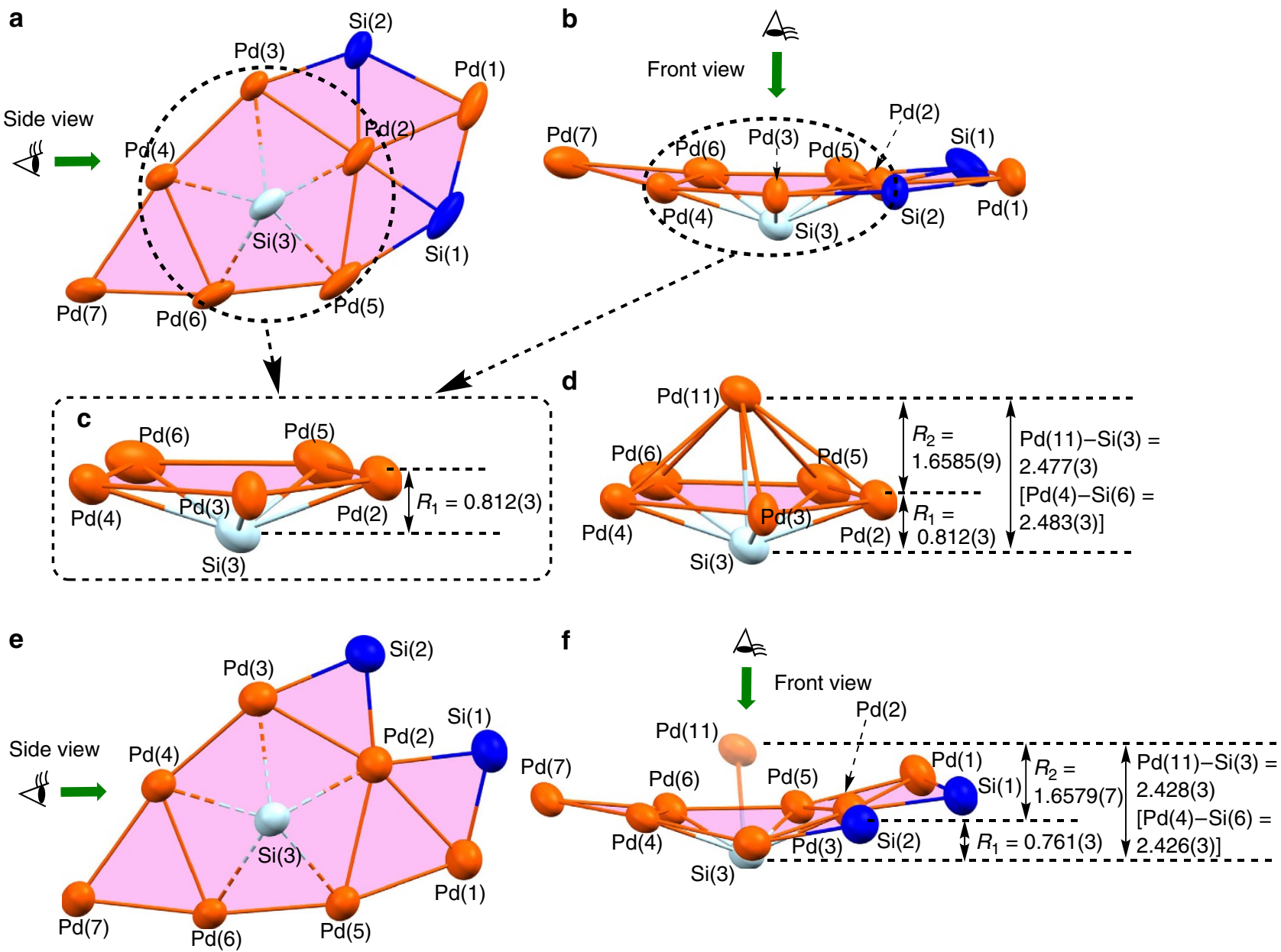

Figure 3 | Core-atom representations of the solid-state structures of $\mathbf{2}$ and 3. (a) Front view of the Sheet I. (b) Side view of the Sheet I. (c) Side view of the pentagonal pyramidal subunit of the Sheet I. (d) Side view of one of the pentagonal bipyramidal substructure of $\mathbf{2}$. (e) Front view of the Sheet III. (f) Side view of the Sheet III. Probability ellipsoids shown at 50\%.

structure. The deviations of all atoms from the plane defined by the $\mathrm{Pd}_{7} \mathrm{Si}_{2}$ nanosheet are within the range of ca. $0.00-0.35 \AA$ for $\mathrm{Pd}_{7}$ sheet I (Supplementary Fig. S7). The deviation is somewhat larger in $\mathrm{Pd}_{7}$ sheet III (ca. 0.08-0.40 ̊) (Supplementary Fig. S8). The remaining silicon atom derived from the silylyne moiety ( $\mathrm{Si}(3)$ in both I and III) is located below the $\mathrm{Pd}_{7} \mathrm{Si}_{2}$ plane. This $\mathrm{Si}$ atom may act as the anchor to reinforce the $\mathrm{Pd}_{7} \mathrm{Si}_{2}$ nanosheet structure.

A characteristic feature of $\mathrm{Pd}_{7}$ sheet $\mathrm{I}$ is that there is a planar pentagonal $\mathrm{Pd}_{5}$ unit consisting of $\operatorname{Pd}(2), \operatorname{Pd}(3), \operatorname{Pd}(4), \operatorname{Pd}(5)$ and $\operatorname{Pd}(6)$, and the $\mathrm{Si}(3)$ atom of the silylyne moiety is located below this pentagonal plane by $0.812(3) \AA$ (Fig. $3 c$ ). One of the other two palladium atoms of $\mathrm{Pd}_{7}$ sheet $\mathrm{I}$, that is, $\mathrm{Pd}(7)$ in Fig. 3a, completes the triangular substructure along with $\operatorname{Pd}(4)$ and $\operatorname{Pd}(6)$. The same characteristic arrangement of $\mathrm{Pd}$ and $\mathrm{Si}$ atoms is also seen in $\mathrm{Pd}_{7}$ sheet III. The orientation of the remaining $\mathrm{Pd}$ atom $(\mathrm{Pd}(1)$ in Fig. $3 \mathrm{a}, \mathrm{e})$ is different between $\mathrm{Pd}_{7}$ sheets I and III: the $\operatorname{Pd}(1)$ atom in $\mathrm{I}$ is located at the edge of the $\mathrm{Pd}_{7} \mathrm{Si}_{2}$ plane to bisect the $\mathrm{Si}(1)-\mathrm{Pd}(2)-\mathrm{Si}(2)$ angle, whereas that in III is arranged next to the $\operatorname{Pd}(5)-P d(6)-P d(7)$ junction to form a bridge over the $\operatorname{Pd}(2)$ and $\mathrm{Pd}(5)$ atoms. The $\mathrm{Pd}-\mathrm{Pd}$ bond distances in $\mathrm{Pd}_{7}$ sheets I and III are within the range of 2.674(2)-2.9998(11) $\AA$ for I (Supplementary Fig. S9) and 2.6168(12)-2.8779(12) $\AA$ for III (Supplementary Fig. S10), which are comparable to those found in previously reported polynuclear palladium clusters, including planar triangular or tetranuclear clusters ${ }^{23-31}$. Two $\mathrm{Si}$ atoms derived from the silylene moiety $(\mathrm{Si}(1)$ and $\mathrm{Si}(2))$ are located on the edge of $\mathrm{Pd}_{7}$ sheets I and III (Fig. 3a,e). It should be mentioned that the coordination number of these silicon atoms is different in $\mathrm{Pd}_{7}$ sheets I and III. The coordination geometry in sheet I is pentacoordinate to form the distorted trigonal bipyramidal structure involving two ${ }^{i} \mathrm{Pr}$ groups and three $\mathrm{Pd}$ atoms, whereas sheet III contains tetracoordinated silicon atoms connected to two ${ }^{i}$ Pr groups and two Pd atoms.

As mentioned above, there are planar pentagonal $\mathrm{Pd}_{5}$ subunits in $\mathrm{Pd}_{7}$ sheets I and III. One silicon atom ( $\mathrm{Si}(3)$ ) located below this plane is connected to these five Pd atoms to form the pentagonal pyramidal structure (Fig. 3c and Supplementary Figs S11 and $\mathrm{S12}$ ). The $\mathrm{Si}(3)$ atom in sheet $\mathrm{I}$ is out of the $\mathrm{Pd}_{5}$ plane by $0.812(3) \AA$, whereas the position of the $\mathrm{Si}(3)$ atom in sheet III deviates from the plane by $0.761(3) \AA$ (Fig. 3f). It is worthwhile to point out that there is an interplane bonding interaction between $\mathrm{Si}(3)$ in $\mathrm{Pd}_{7}$ sheet I and $\mathrm{Pd}(11)$ in $\mathrm{Pd}_{7}$ sheet II (Fig. 3d); this explains the dihedral angle between $\mathrm{Pd}_{7}$ sheets I and II of $37.7^{\circ}$. The $\mathrm{Si}(3)-\mathrm{Pd}(11)$ bond distance of 2.477(3) $\AA$ is longer than that found in common Pd-Si complexes (around 2.3-2.4 ) $^{32,33}$, but shorter than several Pd-Si bonds seen in Osakada's planar $\mathrm{Pd}_{4} \mathrm{Si}_{3}$ cluster $(2.5052(8)-2.5456(7) \AA)^{28}$. Similarly, the interplane bonding of $\mathrm{Si}(3)$ in sheet III and $\operatorname{Pd}(11)$ in sheet IV is the origin of the dihedral angle of $47.7^{\circ}$. As a consequence of the interplane bonding interaction, a pentagonal bipyramidal substructure was formed in the $\mathrm{Pd}_{6} \mathrm{Si}$ unit, and $\mathrm{Si}(3)$ is bound 


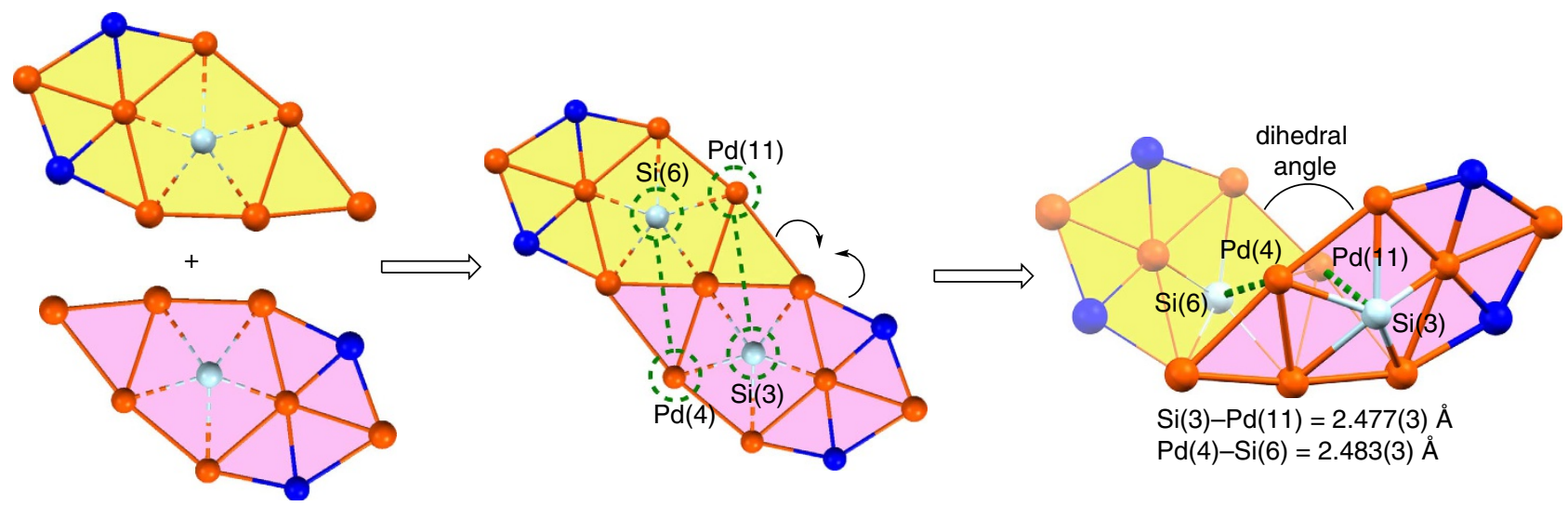

Figure 4 | The conceptual scheme to construct the folding nanosheet. Template synthesis of the folding $\mathrm{Pd}_{11}$ nanosheet with the aid of bridging silylene and silylyne moieties.

to one isopropyl group and six palladium atoms to make the heptacoordinate silicon centre. Silicon atoms stabilized by six metal atoms ( $\mu_{6}$-coordination) are rarely found in the literature ${ }^{34,35}$.

A conceptual scheme to construct the folding $\mathrm{Pd}_{11}\left(\mathrm{Si}^{i} \mathrm{Pr}_{2}\right)_{4}$ $\left(\mathrm{Si} i^{i} \mathrm{Pr}\right)_{2}(\mathrm{CNR})_{10}$ nanosheet structure is depicted in Fig. 4 using compound 2 as a representative example. First, the $\operatorname{Pd}_{7}\left(\mathrm{Si}^{i} \mathrm{Pr}_{2}\right)_{2}$ $\left(\mathrm{Si}{ }^{i} \mathrm{Pr}\right)(\mathrm{CNR})_{5}$ subunits, namely $\mathrm{Pd}_{7}$ nanosheets I and II, were formed with the aid of the bridging silylyne moiety; then sheets I and II were connected to each other to form the planar $\mathrm{Pd}_{11}\left(\mathrm{Si}^{i} \mathrm{Pr}_{2}\right)_{4}$ nanosheet. Bending this planar nanosheet along the linear $\operatorname{Pd}(5)-\operatorname{Pd}(6)-\operatorname{Pd}(7)$ junction afforded the folding $\mathrm{Pd}_{11}\left(\mathrm{Si}^{i} \mathrm{Pr}_{2}\right)_{4}$ nanosheet having a pseudo- $C_{2}$-symmetric structure.

It is of interest that the dihedral angles of the two $\mathrm{Pd}_{7} \mathrm{Si}_{2}$ sheets are different in 2 and $3\left(37.7^{\circ}(2)\right.$ and $\left.47.7^{\circ}(3)\right)$. In both 2 and $\mathbf{3}$, the folding structure is induced by the interaction of $\mathrm{Pd}(11)-\mathrm{Si}(3)$ and $\operatorname{Pd}(4)-\mathrm{Si}(6)$ as described above. The bond lengths of $\operatorname{Pd}(11)-$ $\mathrm{Si}(3)$ and $\mathrm{Pd}(4)-\mathrm{Si}(6)$ in $2(2.477(3)$ and $2.483(3) \AA)$ are slightly longer than those in 3 (2.428(3) and 2.426(3) $\AA$ ). This seems inconsistent with the smaller dihedral angle of 2 than that of $\mathbf{3}$. This contradiction is explained by the larger deviation of the silylyne atoms $(\mathrm{Si}(3)$ or $\mathrm{Si}(6))$ from the planar $\mathrm{Pd}_{7}\left(\mathrm{Si}^{i} \mathrm{Pr}_{2}\right)_{2}$ subunit in $2\left(R_{1}=0.812(3) \AA\right.$ for 2 in Fig. $\left.3 \mathrm{~d}\right)$ than that in 3 $\left(R_{1}=0.761(3) \AA\right.$ in Fig. $\left.3 f\right)$. The shorter $R_{1}$ contributes to increase the dihedral angle, whereas the shorter $\operatorname{Pd}(11)-\operatorname{Si}(3)$ or $\operatorname{Pd}(4)-\operatorname{Si}(6)$ distance takes part in decreasing it. The large dihedral angle of 3 indicates that the former is more effective in determining the dihedral angle.

Molecular structures of 2 and 3 in solution. The ${ }^{1} \mathrm{H}$ and ${ }^{13} \mathrm{C}\left\{{ }^{1} \mathrm{H}\right\}$ NMR spectra of $\mathbf{2}$ are consistent with those expected from their $C_{2}$-symmetric molecular structures (Supplementary Figs S13 and S14). The ${ }^{29} \mathrm{Si}\left\{{ }^{1} \mathrm{H}\right\}$ NMR spectrum of 2 displayed three sharp signals (Supplementary Fig. S15), the significant downfield shifts of which are characteristic of bridging silylene $(\delta 191.85,226.63)$ and silylyne $\left(\delta\right.$ 327.54) moieties $^{36}$. The electrospray ionization mass spectrometry (ESI-MS) spectrum of 2 also supports this, giving two peaks at $\mathrm{m} / z 2519$ and 2602, which are assignable to $\left[2-\mathrm{CN}^{t} \mathrm{Bu}\right]+\mathrm{H}^{+}$and $[2]+\mathrm{H}^{+}$, respectively (Supplementary Figs S16 and S17). These indicate that the $C_{2}$-symmetric $\mathrm{Pd}_{11} \mathrm{Si}_{6}$ units in 2 were maintained in solution. Owing to their thermal instability in solution, the detection of signals in ${ }^{29} \mathrm{Si}\left\{{ }^{1} \mathrm{H}\right\}$ NMR and ESI-MS of 3 was difficult. However, ${ }^{1} \mathrm{H}$ and ${ }^{13} \mathrm{C}\left\{{ }^{1} \mathrm{H}\right\}$ NMR spectra of 3 suggest that the structure in solution is identical with that seen in the solid state (Supplementary Figs S18 and S19). Variable temperature ${ }^{1} \mathrm{H}$ NMR studies showed dynamic behaviour due to site exchange of the isocyanide ligand in 2 but not in 3 (Supplementary Fig. S20).

\section{Discussion}

To the best of our knowledge, $\mathbf{2}$ and $\mathbf{3}$ are the only examples of discrete folding metal nanosheets unequivocally characterized by crystallography and spectroscopy. These $\mathrm{Pd}_{7}$ subunits are the largest planar clusters reported in the literature. More than 40 palladium clusters that are larger than pentanuclear are found in the Cambridge Structural Database (ConQuest version 1.14, February 2013). Most of them were synthesized by tedious multistep procedures in low to medium yields. None of them has a two-dimensional nanosheet structure except Murahashi's $\mathrm{Pd}_{5}$ cluster described above. Therefore, it is remarkable that a folding $\mathrm{Pd}_{11} \mathrm{Si}_{4}$ nanosheet 2 is synthesized in high yield in a single step using the ladder polysilane $\mathbf{1}$ as a template, and another folding $\mathrm{Pd}_{11} \mathrm{Si}_{4}$ nanosheet 3 is formed by exchange of all the $\mathrm{CN}^{t} \mathrm{Bu}$ ligands in 2 to $\mathrm{CN}\left(2,4,6-\mathrm{Me}_{3}-\mathrm{C}_{6} \mathrm{H}_{2}\right)$. During the conversion from 2 to 3 , the array of Pd and Si atoms is altered, and the dihedral angle between the two $\mathrm{Pd}_{7}$ sheets becomes larger. New properties of nano-sized transition metal compounds have attracted attention from a wide array of scientists. Discovery of the ladder polysilane as a template for Pd nanosheets could open the way to synthesize new types of nanometal compounds.

\section{Methods}

Synthesis of materials. Manipulation of air- and moisture-sensitive compounds was carried out under dry nitrogen atmosphere using standard Schlenk tube techniques associated with a high-vacuum line or in the $\mathrm{M}$. Braun Unilab $\mathrm{N}_{2}$-filled glove box maintained at or below 1 p.p.m. of $\mathrm{O}_{2}$ and $\mathrm{H}_{2} \mathrm{O}$. Glassware was dried at $100^{\circ} \mathrm{C}$ for $1 \mathrm{~h}$. All commercial reagents were used as received unless otherwise noted. All solvents (toluene, pentane, diethyl ether, toluene- $\mathrm{d}_{8}$ and $\mathrm{C}_{6} \mathrm{D}_{6}$ ) were distilled over $\mathrm{Na}$ /benzophenone and vacuum transferred to a storage container before use. $\mathrm{Pd}\left(\mathrm{CN}^{t} \mathrm{Bu}\right)_{2}$ was synthesized using a published method ${ }^{2,37}$. Mesityl isocyanide was prepared according to a modified literature procedure ${ }^{38}$.

Decaisopropylbicyclo[2.2.0] hexasilane (1) was synthesized by the method reported in the literature ${ }^{18,20}$.

Synthesis of 2. In a $20 \mathrm{ml}$ Schlenk tube, $\mathrm{Pd}\left(\mathrm{CN}^{t} \mathrm{Bu}\right)_{2}(100 \mathrm{mg}, 0.37 \mathrm{mmol})$ was dissolved in toluene $(3 \mathrm{ml})$, and toluene $(2 \mathrm{ml})$ solution of decaisopropylbicyclo[2.2.0]hexasilane (1) $(20 \mathrm{mg}, 0.03 \mathrm{mmol})$ was added at room temperature. The colour of the initial solution gradually became dark green within $6 \mathrm{~h}$. After mixing this dark green solution for $18 \mathrm{~h}$ at room temperature, the solvent was removed in vacuo. The remaining crude product was washed with pentane $(5 \mathrm{ml} \times 3)$, and dissolved in toluene $(3 \mathrm{ml})$. This toluene solution was centrifuged to remove the small amount of insoluble materials. The supernatant was collected, layered with pentane $(5 \mathrm{ml})$ and cooled to $-35^{\circ} \mathrm{C}$ to afford the dark green crystals of 2 (56 mg, $0.02 \mathrm{mmol}, 65 \%) .{ }^{1} \mathrm{H}$ NMR $\left(600 \mathrm{MHz}, 20^{\circ} \mathrm{C}, \mathrm{C}_{6} \mathrm{D}_{6}\right) \delta 0.95-1.05$ (broad s, 18H), 1.21-1.36 (broad s, $18 \mathrm{H}), 1.30(\mathrm{~s}, 18 \mathrm{H}), 1.40(\mathrm{~s}, 18 \mathrm{H}), 1.44-1.59$ (broad s, 18H), $1.48(\mathrm{~d}, J=7.1 \mathrm{~Hz}, 6 \mathrm{H}), 1.67(\mathrm{~d}, J=7.1 \mathrm{~Hz}, 6 \mathrm{H}), 1.78(\mathrm{~d}, J=7.1 \mathrm{~Hz}$, $6 \mathrm{H}), 1.86(\mathrm{~d}, J=7.1 \mathrm{~Hz}, 6 \mathrm{H}), 1.87(\mathrm{~d}, J=7.1 \mathrm{~Hz}, 6 \mathrm{H}), 1.90(\mathrm{~d}, J=7.1 \mathrm{~Hz}, 6 \mathrm{H}), 1.93$ 
(d, $J=7.1 \mathrm{~Hz}, 6 \mathrm{H}), 1.99(\mathrm{~d}, J=7.1 \mathrm{~Hz}, 6 \mathrm{H}), 2.14(\mathrm{~d}, J=7.1 \mathrm{~Hz}, 6 \mathrm{H}), 2.24(\mathrm{~d}$ $J=7.1 \mathrm{~Hz}, 6 \mathrm{H}), 2.35-2.47(\mathrm{~m}, 10 \mathrm{H}) .{ }^{13} \mathrm{C}$ NMR $\left(150 \mathrm{MHz}, 20{ }^{\circ} \mathrm{C}, \mathrm{C}_{6} \mathrm{D}_{6}\right): \delta 23.58$ $23.89,24.18,24.20,24.74,24.91,25.12,25.36,25.84,26.28,26.62,26.70,26.94$, $28.08,30.14$ (broad s), 30.22, 30.31 (broad, s), 30.76, 31.04 (broad s), 31.49, 54.09 (broad s), 54.41, 54.63, 56.41 (broad s), 150.40, 153.81, 155.02 (broad s), 165.92 (broad s) (one $\mathrm{CMe}_{3}$ and one $C=\mathrm{N}^{t} \mathrm{Bu}$ ) peak are missing presumably owing to the overlapping). ${ }^{29} \mathrm{Si} \mathrm{NMR}\left(119 \mathrm{MHz}, 20^{\circ} \mathrm{C}, \mathrm{C}_{6} \mathrm{D}_{6}\right): \delta 191.85$ (s), 226.63 (s), 327.54 (s); IR (KBr pellet): $v_{\mathrm{N} \equiv \mathrm{C}}=2026-2202$ (broad) $\mathrm{cm}^{-1}$. ESI-MS (THF, $20^{\circ} \mathrm{C}$ ): $m / z=2519\left(\left[2-\mathrm{CN}^{t} \mathrm{Bu}\right]+\mathrm{H}^{+} ; 100 \%\right)$ and $2602\left([2]+\mathrm{H}^{+} ; 49 \%\right)$. Anal calcd for $\mathrm{C}_{80} \mathrm{H}_{160} \mathrm{~N}_{10} \mathrm{Pd}_{11} \mathrm{Si}_{6} ; \mathrm{C} 36.94, \mathrm{H}$ 6.20, N 5.38; found: C 36.57, H 6.05, N 5.09.

Synthesis of 3. In a $20 \mathrm{ml}$ Schlenk tube, $\mathrm{Pd}_{11}\left(\mathrm{Si}^{i} \mathrm{Pr}_{2}\right)_{4}\left(\mathrm{Si}{ }^{i} \mathrm{Pr}\right)_{2}\left(\mathrm{CN}^{t} \mathrm{Bu}\right)_{10}(2)(50 \mathrm{mg}$, $0.02 \mathrm{mmol}$ ) was dissolved in toluene $(3 \mathrm{ml})$, and toluene $(2 \mathrm{ml})$ solution of mesityl isocyanide $(28 \mathrm{mg}, 0.19 \mathrm{mmol})$ was added at $-35^{\circ} \mathrm{C}$. After the resulting mixture was stirred for $12 \mathrm{~h}$ at $-35^{\circ} \mathrm{C}$, the solvent was removed under reduced pressure. The residue was dissolved in pentane $(5 \mathrm{ml})$, and centrifuged to remove the small amount of insoluble materials. The supernatant was collected, and the solvent was evaporated in vacuo. The remaining powder was dissolved in diethyl ether $(3 \mathrm{ml})$, and cooled to $-35^{\circ} \mathrm{C}$ to afford the dark green crystals of $3(34 \mathrm{mg}, 0.01 \mathrm{mmol}$, $55 \%) .{ }^{1} \mathrm{H}$ NMR $\left(600 \mathrm{MHz}, 20^{\circ} \mathrm{C}, \mathrm{C}_{6} \mathrm{D}_{6}\right): \delta 1.21-1.31(\mathrm{~m}, 2 \mathrm{H}), 1.47(\mathrm{~d}, J=7.7 \mathrm{~Hz}$, $6 \mathrm{H}), 1.53(\mathrm{~d}, J=7.1 \mathrm{~Hz}, 6 \mathrm{H}), 1.56(\mathrm{~d}, J=7.7 \mathrm{~Hz}, 6 \mathrm{H}), 1.58$ (broad s, $6 \mathrm{H}), 1.59$ $(\mathrm{d}, J=7.7 \mathrm{~Hz}, 6 \mathrm{H}), 1.80($ broad s, $6 \mathrm{H}), 1.82-1.86(\mathrm{~m}, 18 \mathrm{H}), 1.88(\mathrm{~d}, J=7.7 \mathrm{~Hz}, 6 \mathrm{H})$, $1.89(\mathrm{~s}, 12 \mathrm{H}), 1.90(\mathrm{~s}, 6 \mathrm{H}), 1.99(\mathrm{~s}, 6 \mathrm{H}), 2.03(\mathrm{~d}, J=7.1 \mathrm{~Hz}, 6 \mathrm{H}), 2.12(\mathrm{~d}, J=7.1 \mathrm{~Hz}$, $6 \mathrm{H}), 2.15$ (broad s, $18 \mathrm{H},), 2.20(\mathrm{~s}, 12 \mathrm{H}), 2.22(\mathrm{~d}, J=7.7 \mathrm{~Hz}, 6 \mathrm{H}), 2.50(\mathrm{~s}, 12 \mathrm{H}), 2.56$ (s, 12H), 2.90-3.02 (m, 2H). ${ }^{13} \mathrm{C}$ NMR $\left(150 \mathrm{MHz}, 20{ }^{\circ} \mathrm{C}, \mathrm{C}_{6} \mathrm{D}_{6}\right): \delta 14.29$ (broad s), $18.55,18.82,19.09,19.27,19.92,20.94,20.96,21.08,21.13$ (broad s), 22.04, 22.08, $22.25,22.51,22.60,22.74,24.16,24.93,25.40,26.19,27.97,29.61,30.19,34.45$, $35.40,126.80,128.63,128.88,128.90,129.31,130.66,132.06,132.11,133.55,133.65$, $133.68,133.93,133.99,134.37,134.44,134.48,134.49,136.07,136.97,165.95$, $168.71,168.75,173.34,180.05$ (one aromatic peak is missing presumably owing to the overlapping). IR (KBr pellet): $v_{\mathrm{N} \equiv \mathrm{C}}=1968-2160$ (broad) $\mathrm{cm}^{-1}$. Anal calcd for $\mathrm{C}_{130} \mathrm{H}_{180} \mathrm{~N}_{10} \mathrm{Pd}_{11} \mathrm{Si}_{6}$; C 48.46, H 5.63, N 4.35; found: C 48.19, H 5.43, N 4.08.

X-ray data collection and reduction. X-ray crystallography was performed on a Rigaku Saturn CCD area detector with graphite monochromated Mo-K $\alpha$ radiation $(\lambda=0.71070 \mathrm{~A})$. The data were collected at $123(2) \mathrm{K}$ using $\omega$ scan in the $\theta$ range of $3.03 \leq \theta \leq 27.54 \mathrm{deg}(2)$ and $3.05 \leq \theta \leq 27.54 \mathrm{deg}$ (3). The data obtained were processed using Crystal-Clear (Rigaku) on a Pentium computer, and were corrected for Lorentz and polarization effects. The structures were solved by direct methods, and expanded using Fourier techniques. Hydrogen atoms were refined using the riding model. The final cycle of full-matrix least-squares refinement on $F^{2}$ was based on 24,780 observed reflections and 975 variable parameters for 2 and 31,308 observed reflections and 1,296 variable parameters for 3 . Neutral atom scattering factors were taken from Cromer and Waber. All calculations were performed using the CrystalStructure crystallographic software package. Two of ten ${ }^{t} \mathrm{Bu}$ groups in $\mathbf{2}$ were observed at two positions with the site occupancy factor of 0.50:0.50, and these ${ }^{t} \mathrm{Bu}$ groups were refined isotropically. The disordered pentane solvent was found in the unit cell of 2 . One of the ${ }^{i} \mathrm{Pr}$ group of 3 showed the disorder in the crystal. The site occupancy factor of 0.30:0.30:0.40 was determined, and the carbon atoms derived from this ${ }^{i} \mathrm{Pr}$ group was refined isotropically. It was found that three mesityl groups of $\mathbf{3}$ were highly disordered, thus the carbon atoms of them were refined using geometrical restraint. Details of the final refinement are summarized in the Supplementary Table S1.

\section{References}

1. Geim, A. K. Random walk to graphene (Nobel Lecture). Angew. Chem. Int. Ed. 50, 6967-6985 (2011)

2. Novoselov, K. S. Graphene: materials in the flatland (Nobel Lecture). Angew. Chem. Int. Ed. 50, 6986-7002 (2011).

3. Rao, C. N. R., Sood, A. K., Subrahmanyam, K. S. \& Govindaraj, A. Graphene: the new two-dimensional nanomaterial. Angew. Chem. Int. Ed. 48, 7752-7777 (2009).

4. Guo, S. \& Dong, S. Graphene nanosheet: synthesis, molecular engineering, thin film, hybrids, and energy and analytical applications. Chem. Soc. Rev. 40, 2644-2672 (2011)

5. Osada, M. \& Sasaki, T. Two-dimensional dielectric nanosheets: novel nanoelectronics from nanocrystal building blocks. Adv. Mater. 24, 210-228 (2012).

6. Adams, R. D., Zhang, Q. \& Yang, X. Two-dimensional bimetallic carbonyl cluster complexes with new properties and reactivities. J. Am. Chem. Soc. 133, 15950-15953 (2011).

7. Brayhaw, S. K. et al. $\left[\mathrm{Rh}_{7}\left(\mathrm{PiPr}_{3}\right)_{6} \mathrm{H}_{18}\right]\left[\mathrm{BAr}_{4}{ }_{4}\right]_{2}$ : a molecular $\mathrm{Rh}(111)$ surface decorated with 18 hydrogen atoms. Angew. Chem. Int. Ed. 46, 7844-7848 (2007).

8. Kong, G., Harakas, G. N. \& Whittlesey, B. R. An unusual transition metal cluster containing a seven metal atom plane. Synthesis and crystal structures of
$[\mathrm{Mn}]\left[\mathrm{Mn}_{7}(\mathrm{THF})_{6}(\mathrm{CO})_{12}\right]_{2}, \mathrm{Mn}_{3}(\mathrm{THF})_{2}(\mathrm{CO})_{10}$, and $\left[\mathrm{Mn}(\mathrm{THF})_{6}\right]\left[\mathrm{Mn}(\mathrm{CO})_{5}\right]_{2}$. J. Am. Chem. Soc. 117, 3502-3509 (1995).

9. Doyle, G., Eriksem, K. A. \& Van Engen, D. Mixed copper/iron clusters. The preparation and structure of the large planar cluster anions, $\mathrm{Cu}_{3} \mathrm{Fe}_{3}(\mathrm{CO})_{12}^{3-}$ and $\mathrm{Cu}_{5} \mathrm{Fe}_{4}(\mathrm{CO})_{16}^{3-}$. J. Am. Chem. Soc 108, 445-451 (1986).

10. Murahashi, T. et al. Discrete sandwich compounds of monolayer palladium sheets. Science 313, 1104-1107 (2006).

11. Murahashi, T., Inoue, R., Usui, K. \& Ogoshi, S. Square tetrapalladium sheet sandwich complexes: cyclononatetraenyl as a versatile face-capping ligand. J. Am. Chem. Soc. 131, 9888-9889 (2009).

12. Murahashi, T., Kato, N., Uemura, T. \& Kurosawa, H. Rearrangement of a $\mathrm{Pd}_{4}$ skeleton from a $1 \mathrm{D}$ Chain to a $2 \mathrm{D}$ sheet on the face of a perylene or fluoranthene ligand caused by exchange of the binder molecule. Angew. Chem. Int. Ed. 46, 3509-3512 (2007).

13. Murahashi, T. et al. Reductive coupling of metal triangles in sandwich complexes. J. Am. Chem. Soc. 130, 8586-8587 (2008).

14. Murahashi, T., Takase, K., Oka, M. \& Ogoshi, S. Oxidative dinuclear addition of a $\mathrm{Pd}^{\mathrm{I}}-\mathrm{Pd}^{\mathrm{I}}$ moiety to arenes: generation of $\mu-\eta^{3}: \eta^{3}-$ Arene- $\mathrm{Pd}^{\mathrm{II}}{ }_{2}$ species. J. Am. Chem. Soc. 133, 14908-14911 (2011)

15. Murahashi, T., Usui, K., Inoue, R., Ogoshi, S. \& Kurosawa, H. Metallocenoids of platinum: syntheses and structures of triangular triplatinum sandwich complexes of cycloheptatrienyl. Chem. Sci. 2, 117-122 (2011).

16. Murahashi, T., Fujimoto, M., Kawabata, Y., Inoue, R., Ogoshi, S. \& Kurosawa, H. Discrete triangular tripalladium sandwich complexes of arenes. Angew. Chem. Int. Ed. 46, 5440-5443 (2007).

17. Kyushin, S. \& Matsumoto, H. Ladder polysilanes. Adv. Organomet. Chem. 49, 133-166 (2003)

18. Matsumoto, H., Miyamoto, H., Kojima, N. \& Nagai, Y. The first bicyclo[2.2.0] hexasilane system: synthesis of decaisopropylhexasilabicyclo[2.2.0]hexane. J. Chem. Soc. Chem. Commun. 1316-1317 (1987).

19. Kyushin, S., Kawabata, M., Okayasu, T., Yagihashi, Y., Matsumoto, H. \& Goto, M. Selective Si-Si bond cleavage in decaisopropylbicyclo[2.2.0]hexasilane. A route to sterically 1,4-dichlorocyclohexasilanes. Chem. Lett. 23, 221-224 (1994).

20. Matsumoto, H., Miyamoto, H., Kojima, N., Nagai, Y. \& Goto, M. X-ray strucutre analysis of a bicyclo[2.2.0] hexasilane, decaisopropylhexasilabicyclo[2.2.0] hexane. Chem. Lett. 17, 629-631 (1988).

21. Suginome, M., Kato, Y., Takeda, N., Oike, H. \& Ito, Y. Reactions of a spiro trisilane with palladium complexes: synthesis and structure of tris(organosilyl) $\mathrm{CpPd}^{\mathrm{IV}}$ and bis(organosilyl)( $i$-organosilylene) $\mathrm{Pd}_{2}{ }_{2}$ complexes. Organometallics 17, 495-497 (1998).

22. Suginome, M., Oike, H., Park, S. -S. \& Ito, Y. Reactions of Si-Si $\sigma$-bonds with bis $(t$-alkyl isocyanide)palladium $(0)$ complexes. Synthesis and reactions of cyclic bis(organosilyl)palladium complexes. Bull. Chem. Soc. Jap 69, 289-299 (1996).

23. Yamada, T., Mawatari, A., Tanabe, M., Osakada, K. \& Tanase, T. Planar tetranuclear and dumbbell-shaped octanuclear palladium complexes with bridging silylene ligands. Angew. Chem. Int. Ed. 48, 568-571 (2009).

24. Burrows, A. D., Michael, D. \& Mingos, M. P. The chemistry of group 10 metal triangulo clusters. Coord. Chem. Rev. 154, 19-69 (1996).

25. Burrows, A. D., Michael, D. \& Mingos, M. P. Palladium cluster compounds. Transition Met. Chem 18, 129-148 (1993).

26. Mednikov, E. G. \& Dahl, L. F. Nanosized $\mathrm{Pd}_{37}(\mathrm{CO})_{28}\left\{\mathrm{P}(p \text {-Tolyl })_{3}\right\}_{12}$ containing geometrically unprecedented central 23-atom interpenetrating tri-icosahedral palladium kernel of double icosahedral units: its postulated metal-core evolution and resulting stereochemical implications. J. Am. Chem. Soc 130 , 14813-14821 (2005).

27. Mednikov, E. G., Wittayakun, J. \& Dahl, L. F. Synthesis and stereochemical/ electrochemical analyses of cuboctahedral-based $\mathrm{Pd}_{23}(\mathrm{CO})_{x}\left(\mathrm{PR}_{3}\right)_{10}$ clusters $\left(x=20\right.$ with $\mathrm{R}_{3}=\mathrm{Bu}^{n}{ }_{3}, \mathrm{Me}_{2} \mathrm{Ph} ; x=20,21,22$ with $\left.\mathrm{R}_{3}=\mathrm{Et}_{3}\right)$ : geometrically analogous $\mathrm{Pd}_{23}\left(\mathrm{PEt}_{3}\right)_{10}$ fragments with variable carbonyl ligations and resulting implications. J. Cluster Sci 16, 429-453 (2005).

28. Tanabe, M., Ishikawa, N., Chiba, M., Ide, T., Osakada, K. \& Tanase, T. Tetrapalladium complex with bridging germylene ligands. Structural change of the planar $\mathrm{Pd}_{4} \mathrm{Ge}_{3}$ core. J. Am. Chem. Soc. 133, 18598-18601 (2011).

29. Francis, C. G., Khan, S. I. \& Morton, P. R. Metal vapor routes to metalisocyanide complexes. Synthesis and molecular structure of tris $(\mu$-cyclohexyl isocyanide)-tris(cyclohexyl isocyanide)-triangulo-tripalladium. Inorg. Chem 23, 3680-3681 (1984).

30. Shimada, S., Li, Y.-H., Choe, Y. -K., Tanaka, M., Bao, M. \& Uchimaru, T. Multinuclear palladium compounds containing palladium centers ligated by five silicon atoms. Proc. Natl Acad. Sci. USA 127, 7758-7763 (2007).

31. Moiseev, I. I., Stromnova, T. A., Vargaftig, M. N., Mazo, G. J., Kuz'Mina, L. G. \& Struchkov, Y. T. New palladium carbonyl clusters: $X$-ray crystal structure of $\left[\mathrm{Pd}_{4}(\mathrm{CO})_{4}(\mathrm{OAc})_{4}\right] \cdot(\mathrm{AcOH})_{2}$. J. Chem. Soc. Chem. Commun. 27-28 (1978).

32. Corey, J. Y. Reactions of hydrosilanes with transition metal complexes and characterization of the products. Chem. Rev 111, 863-1071 (2011). 
33. Corey, J. Y. \& Braddock-Wilking, J. Reactions of hydrosilanes with transitionmetal complexes: formation of stable transition-metal silyl complexes. Chem. Rev 99, 175-292 (1999).

34. Purath, A. et al. Synthesis and structure of a neutral SiAl ${ }_{14}$ cluster. J. Am. Chem. Soc. 122, 6955-6959 (2000).

35. Mackay, K. M., Nicholson, B. K., Robinson, W. T. \& Sims, A. W. A paramagnetic cobalt carbonyl cluster anion with an encapsulated silicon atom; preparation and structure of $\left[\mu_{8}-\mathrm{SiCo}_{9}(\mathrm{CO})_{21}\right]^{2-}$. J. Chem. Soc. Chem. Commun. 1276-1277 (1984)

36. Ogino, H. \& Tobita, H. Bridged silylene and germylene complexes. Adv. Organomet. Chem 42, 223-290 (1998).

37. Otsuka, S., Nakamura, A. \& Tatsuno, Y. Oxygen complexes of nickel and palladium. Formation, structure, and reactivities. J. Am. Chem. Soc. 91, 69946999 (1969)

38. Walborsky, H. M. \& Niznik, G. E. Synthesis of isonitriles. J. Org. Chem. 37, 187-190 (1972).

\section{Acknowledgements}

This work was supported by the Core Research Evolutional Science and Technology (CREST) Program of Japan Science and Technology Agency (JST) Japan, and this work was performed under the Cooperative Research Program of 'Network Joint Research Center for Materials and Devices'.

\section{Author contributions}

The idea and plans for this research were developed by Y.S., S.K. and H.N. Experiments were performed by Y.S., R.H., K.O. and S.K. The data were analysed by Y.S., R.H., K.O., S.K. and H.N. The manuscript was written by Y.S., S.K. and H.N. All authors discussed the results.

\section{Additional information}

Accession codes: The X-ray crystallographic coordinates for structures reported in this Article have been deposited at the Cambridge Crystallographic Data Centre (CCDC), under deposition numbers CCDC 924691 and 924692 . These data can be obtained free of charge from The Cambridge Crystallographic Data Centre via www.ccdc.cam.ac.uk/ data_request/cif.

Supplementary Information accompanies this paper at http://www.nature.com/ naturecommunications

Competing financial interests: The authors declare no competing financial interests.

Reprints and permission information is available online at http://npg.nature.com/ reprintsandpermissions/

How to cite this article: Sunada, Y. et al. A ladder polysilane as a template for folding palladium nanosheets. Nat. Commun. 4:2014 doi: 10.1038/ncomms3014 (2013). 